\title{
Comparison of 12-Month Outcomes with Zotarolimus- and Paclitaxel-Eluting Stents: A Meta-Analysis
}

\author{
Rohit S. Loomba, ${ }^{1}$ Suraj Chandrasekar, ${ }^{1}$ Neil Malhotra, ${ }^{2}$ and Rohit R. Arora ${ }^{1}$ \\ ${ }^{1}$ Department of Cardiology, James A Lovell Federal Health Center/Chicago Medical School, 3001 Green Bay Road, \\ North Chicago, IL 60064, USA \\ ${ }^{2}$ Department of Medicine, Saint Louis University Medical School, 1402 South Grand, St. Louis, MO 63104, USA
}

Correspondence should be addressed to Rohit S. Loomba, loomba.rohit@gmail.com

Received 17 February 2011; Accepted 1 April 2011

Academic Editors: A. R. Galassi, S. Hirohata, and S.-J Park

Copyright () 2011 Rohit S. Loomba et al. This is an open access article distributed under the Creative Commons Attribution License, which permits unrestricted use, distribution, and reproduction in any medium, provided the original work is properly cited.

Revascularization after myocardial infarction is often achieved via percutaneous coronary intervention, which often entails stenting. Drug-eluting stents have shown benefits over bare metal stents in this setting, and a variety of drug-eluting stents are now available, including sirolimus-, paclitaxel-, and zotarolimus-eluting stents. There are studies that have compared the various drug-eluting stents and this meta-analysis pools data comparing 12-month clinical outcomes of zotarolimus- and paclitaxeleluting stents. End points studied were myocardial infarction, major adverse cardiac events, cardiac death, all-cause death, stent thrombosis, target vessel revascularization, and target lesion revascularization. There was a statistically significant reduction in risk of myocardial infarction (odds ratio, 0.250 , confidence interval, 0.160 to 0.392 ) and statistically insignificant reductions in major adverse cardiac events (odds ratio, 0.813, confidence interval, 0.656 to 1.007), cardiac death (odds ratio, 0.817, confidence interval, 0.359 to 1.857 ), all cause death (odds ratio, 0.820 , confidence interval, 0.443 to 1.516 ), and target lesion revascularization (odds ratio, 0.936 , confidence interval 0.702 to 1.247 ). There was a statistically significant increase in target vessel revascularization (odds ratio, 1.336, confidence interval, 1.003 to 1.778 ) and a statistically insignificant increase in stent thrombosis (odds ratio, 1.174, confidence interval, 0.604 to 2.280). These findings are similar to the individual studies although other studies have noted increased late loss with zotarolimus-eluting stents and this current data associated with late loss should be kept in mind when makimg clinical decisions regarding sent selection.

\section{Introduction}

Management of coronary disease has evolved immensely over the past 40 years. Coronary artery bypass grafting (CABG) has become less common with the development of percutaneous coronary intervention (PCI). PCI has now become standard of care for managing patients with myocardial infarction (MI), with stenting techniques replacing balloon angioplasty. The increased role of stenting has led to the development of drug-eluting stents which have been shown to lower restenosis rates when compared to bare metal stents, without increasing the risk of MI or death [1]. There are various options when selecting drug-eluting stents, including paclitaxel-, sirolimus, and zotarolimus-eluting stents. With several options when it comes to drug-eluting stents, the need for evidence-based guidelines has become evident. This meta-analysis pools data from studies comparing 12 month clinical outcomes of newer zotarolimus-eluting stents to commonly used paclitaxel-eluting stents.

\section{Methods}

2.1. Literature Sources, Search Terms, and Study Selection. Systematic review of medical literature was carried out to identify studies evaluating outcomes after stenting with zotarolimus- and paclitaxel-eluting stents. Studies were collected by searching MEDLINE and the Cochrane Library using web-based search engines such as OVID. All relevant studies were assessed for inclusion regardless of time of 


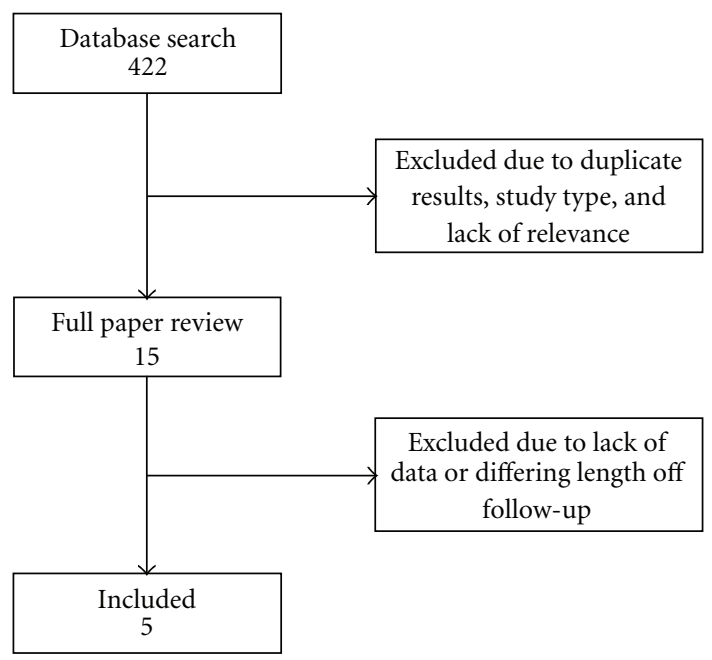

Figure 1: Overview of study selection.

TABLE 1: Summary of heterogeneity analysis.

\begin{tabular}{lcccc}
\hline & $Q$ & $d F$ & $P$-value & Result \\
\hline MI & 1.6724 & 3 & .6431 & Homogenous \\
MACE & 3.1045 & 2 & .2118 & Homogenous \\
Cardiac death & 0.8357 & 3 & .8357 & Homogenous \\
All-cause death & 3.1045 & 2 & .2118 & Homogenous \\
$\begin{array}{l}\text { Stent thrombosis } \\
\text { Target vessel }\end{array}$ & 0.2858 & 3 & .9627 & Homogenous \\
$\begin{array}{l}\text { revascularization } \\
\text { Target lesion }\end{array}$ & 6.7677 & 3 & .0797 & Homogenous \\
revascularization & 5.8443 & 2 & .0538 & Homogenous \\
\hline
\end{tabular}

$d F$ : degrees of freedom.

publication. Search terms used include zotarolimus, paclitaxel, drug-eluting stents, stent thrombosis, stent outcomes, and combinations of these terms. Hand search for articles, abstracts, and reviews was also conducted using references of already identified studies. Explicit inclusion and exclusion criteria were used to evaluate the titles and abstracts from collected articles on basis of the aforementioned criteria for potential inclusion. Figure 1 outlines study selection.

2.2. End Points and Definitions. A total of seven end points were extracted from five studies [2-6]. End points studied were myocardial infarction (MI), major adverse cardiac events (MACE), cardiac death, all-cause death, stent thrombosis, target vessel revascularization, and target lesion revascularization. Only studies with corresponding endpoint definitions were included.

2.3. Data Extraction and Quality Assessment. After articles were collected and screened for inclusion, full articles were retrieved for titles thought to fulfill inclusion criteria. Data was then extracted while also scoring the methodological quality of each study.
2.4. Statistical Analysis. Individual patient data from included studies was not available, so a meta-analysis was done using summary statistics from each. Statistical analysis was performed using the MedCalc software package (Version 11.3, Mariakerke, Belgium). Cochrane's Q statistics were calculated and used to determine the heterogeneity of the studies for each end point. The end points demonstrated homogeneous results so the fixed effects model was used for analysis (Table 1). A two-sided alpha error less than 0.05 was considered to be statistically significant. Heterogeneity analysis is summarized in Table 1.

\section{Results}

3.1. Baseline Characteristics. The characteristics of each individual trial had no significant differences within studies (Table 2). Results of the meta-analysis are shown in Figures $2,3,4,5,6,7$, and 8 . There were no significant differences in patient demographics between both groups.

3.2. Myocardial Infarction. There was a significant decrease in risk of myocardial infarction in the zotarolimus group (odds ratio, 0.250, confidence interval, 0.160 to 0.392 ).

3.3. Major Adverse Cardiac Events. There was a slightly lower risk of major adverse cardiac events in the zotarolimus group; this finding, however, is statistically insignificant (odds ratio, 0.813 , confidence interval, 0.656 to 1.007 ).

3.4. Cardiac Death. There was a slightly lower risk of cardiac death in the zotarolimus group; this finding, however, is statistically insignificant (odds ratio, 0.817, confidence interval, 0.359 to 1.857 ).

3.5. All-Cause Death. There was a slightly lower risk of allcause death in the zotarolimus group; this finding, however, is statistically insignificant (odds ratio, 0.820, confidence interval, 0.443 to 1.516 ).

3.6. Stent Thrombosis. There was a slightly higher risk of stent thrombosis in the zotarolimus group; this finding, however, is statistically insignificant (odds ratio, 1.174, confidence interval, 0.604 to 2.280 ).

3.7. Target Vessel Revascularization. There was a significantly higher risk of target vessel revascularization in the zotarolimus group (odds ratio, 1.336, confidence interval, 1.003 to 1.778$)$.

3.8. Target Lesion Revascularization. Risk of target lesion was lower in the zotarolimus group; this finding, however, is statistically insignificant (odds ratio, 0.936, confidence interval 0.702 to 1.247 ). 
TABLE 2: Baseline characteristics of patients in included studies.

\begin{tabular}{|c|c|c|c|c|c|}
\hline & Chevalier et al. & Choi et al. & Kim et al. & Park et al. & Leon et al. \\
\hline \multicolumn{6}{|c|}{ Number studied } \\
\hline PES & 197 & 153 & 105 & 884 & 775 \\
\hline ZES & 199 & 86 & 47 & 883 & 773 \\
\hline \multicolumn{6}{|l|}{ Age } \\
\hline PES & $63+/-11$ & $61.54+/-12.22$ & $63+/-9$ & $62.0+/-9.6$ & $63.6+/-11.0$ \\
\hline Zes & $63+/-10$ & $60.24+/-11.76$ & $59+/-12$ & $61.7+/-9.3$ & $63.5+/-11.1$ \\
\hline \multicolumn{6}{|c|}{ Gender (male) } \\
\hline PES & $77 \%$ & $100(65.4 \%)$ & $76(72.4 \%)$ & $582(65.8 \%)$ & $531(68.5 \%)$ \\
\hline ZES & $75 \%$ & $69(80.2 \%)$ & $37(78.7 \%)$ & $586(66.4 \%)$ & $517(66.9 \%)$ \\
\hline \multicolumn{6}{|c|}{ Vessel location (LAD) } \\
\hline PES & $40 \%$ & $72(47.1 \%)$ & $45(42.9 \%)$ & $611(50.7 \%)$ & $321(41.5 \%)$ \\
\hline ZES & $48 \%$ & $45(52.3 \%)$ & $30(63.8 \%)$ & $622(52.3 \%)$ & $326(42.2 \%)$ \\
\hline \multicolumn{6}{|c|}{ Vessel location (LCx) } \\
\hline PES & $19 \%$ & $29(19.0 \%)$ & $15(14.2 \%)$ & $253(21.0)$ & $202(26.1 \%)$ \\
\hline ZES & $24 \%$ & $10(11.6 \%)$ & $2(4.3 \%)$ & $252(21.2 \%)$ & $208(26.9 \%)$ \\
\hline \multicolumn{6}{|c|}{ Vessel location (RCA) } \\
\hline PES & $41 \%$ & $52(34.0 \%)$ & $45(42.9)$ & $340(28.2 \%)$ & $251(32.4 \%)$ \\
\hline ZES & $28 \%$ & $31(36.0 \%)$ & $15(31.9 \%)$ & $316(26.6)$ & $238(30.8 \%)$ \\
\hline \multicolumn{6}{|c|}{ Diabetes mellitus } \\
\hline PES & $26 \%$ & $104(68.0 \%)$ & $23(21.9 \%)$ & $245(27.7 \%)$ & $236(30.5 \%)$ \\
\hline ZES & $22 \%$ & $64(74.4 \%)$ & $12(25.5 \%)$ & $268(30.4 \%)$ & $241(31.2 \%)$ \\
\hline \multicolumn{6}{|c|}{ Hypertension } \\
\hline PES & $67 \%$ & $86(56.2 \%)$ & $50(47.6 \%)$ & $540(61.1 \%)$ & $640(82.6 \%)$ \\
\hline ZES & $69 \%$ & $53(61.6 \%)$ & $20(43.5 \%)$ & $552(62.5 \%)$ & $614(79.4 \%)$ \\
\hline \multicolumn{6}{|c|}{ Hyperlipidemia } \\
\hline PES & $72 \%$ & $104(68.2 \%)$ & $43(41.3 \%)$ & $446(50.5 \%)$ & $657(84.8 \%)$ \\
\hline ZES & $78 \%$ & $57(66.3 \%)$ & $18(39.1 \%)$ & $466(52.8 \%)$ & $629(81.4)$ \\
\hline
\end{tabular}

PES: paclitaxel-eluting stent; ZES: zotarolimus-eluting stent; LAD: left anterior descending coronary artery; LCx: left circumflex coronary artery; RCA: right coronary artery.

\section{Discussion}

This meta-analysis shows that zotarolimus-eluting stents may not differ with respect to outcomes studied here. Other studies have had similar results with these particular outcomes when comparing zotarolimus- and paclitaxel-eluting stents [3-5]. A two-year follow-up study by Cicek et al., however, did find a statistically significant decrease in MACE, coronary artery bypass graft, and Q wave MI, associated with zotarolimus-eluting stents when compared to paclitaxeleluting stents. No major differences were reported by this study for all-cause death, target vessel revascularization, and non-target-vessel revascularization [7]. This study was nonrandomized and had a small number of patients; so the true value of these findings is questionable. Where the two stent varieties do seem to differ is in late loss, an end point not included in this 12-month outcome metaanalysis. Zotarolimus-eluting stents have been documented to demonstrate greater late loss than paclitaxel-eluting stents $[2,3,8]$. This study, however, did not find an increase in stent thrombosis with zotarolimus-eluting stents.
Drug-eluting stents have significantly reduced the rate of restenosis when compared to bare metal stents [9] and have assumed a larger role in the management of STEMI as primary percutaneous coronary intervention has become standard of care. When compared to bare metal stents, drugeluting stents have shown greater 1-year event-free survival rates [10-12] and similar safety profiles $[13,14]$ in STEMI patients. Sirolimus- and paclitaxel-eluting stents have been used with success for primary PCI in standard STEMI cases as well as those complicated by anatomical variations [15].

The ENDEAVOR IV trial studied the cost-effectiveness of zotarolimus-eluting stents and concluded that costeffectiveness was similar to that of paclitaxel-eluting stents. Analysis took into account quality-adjusted survival, medical costs, and relative cost-cost effectiveness [16].

While zotarolimus-eluting stents have been associated with greater in-stent late loss when compared to paclitaxeleluting stents, this may not have much clinical impact as studies have noted that low mean values of in-stent late loss are not associated with the risk of stent thrombosis [17]. 


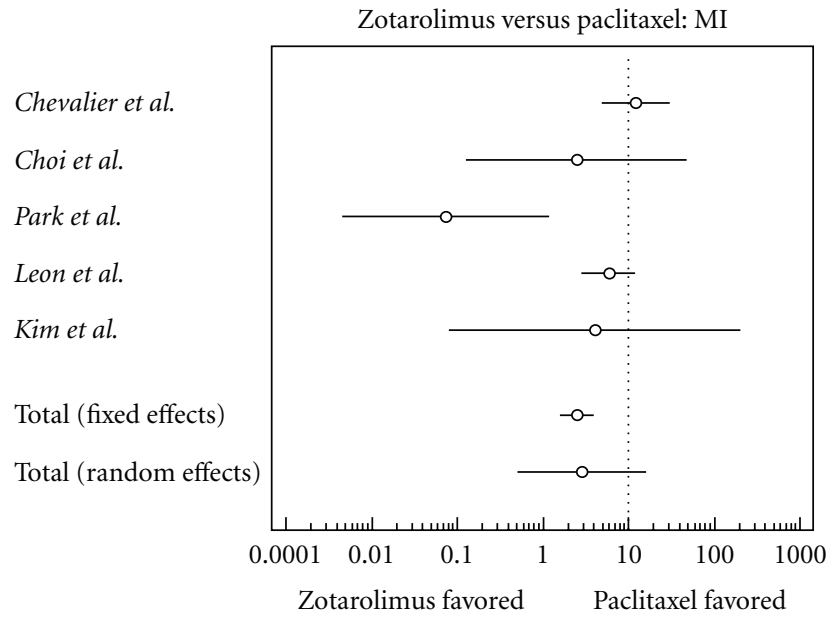

FIGURE 2: Forest plot comparing risk of myocardial infarction.

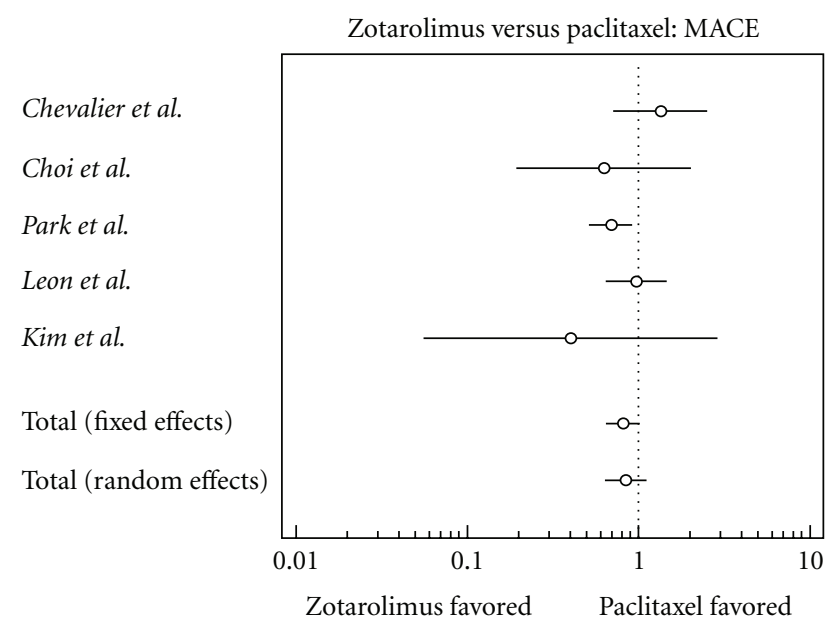

FIGURE 3: Forest plot comparing risk of major adverse cardiac events.

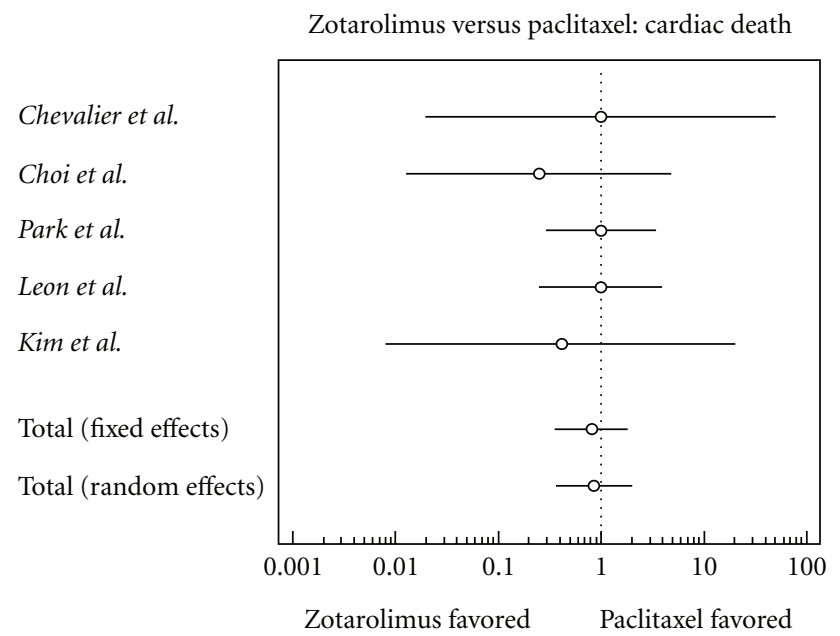

FIGURE 4: Forest plot comparing risk of cardiac death.

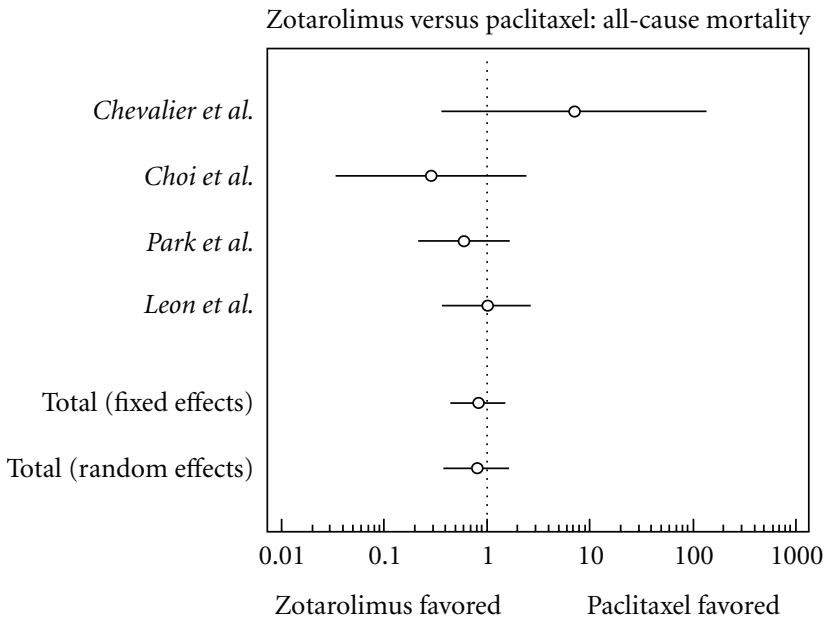

FIGURE 5: Forest plot comparing risk of all-cause mortality.

Zotarolimus versus paclitaxel: stent thrombosis

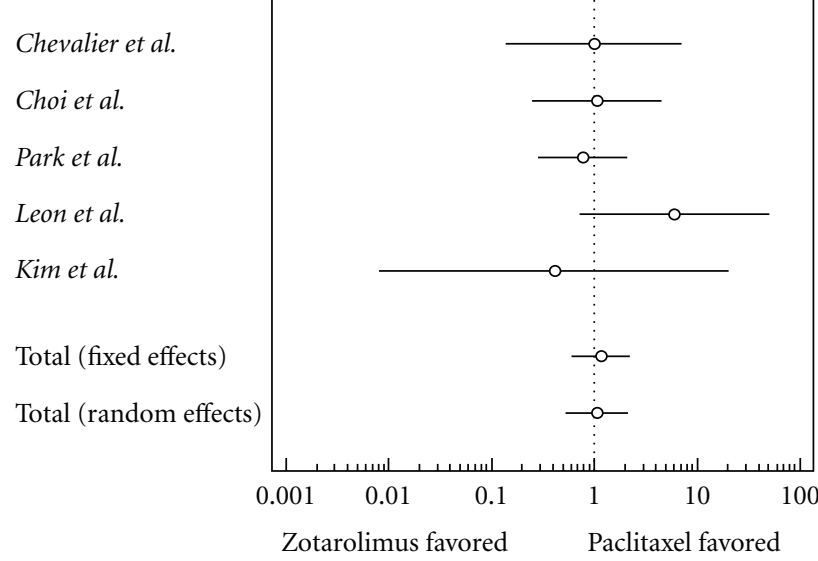

FIGURE 6: Forest plot comparing risk of stent thrombosis.

Zotarolimus versus paclitaxel: target vessel revascularization

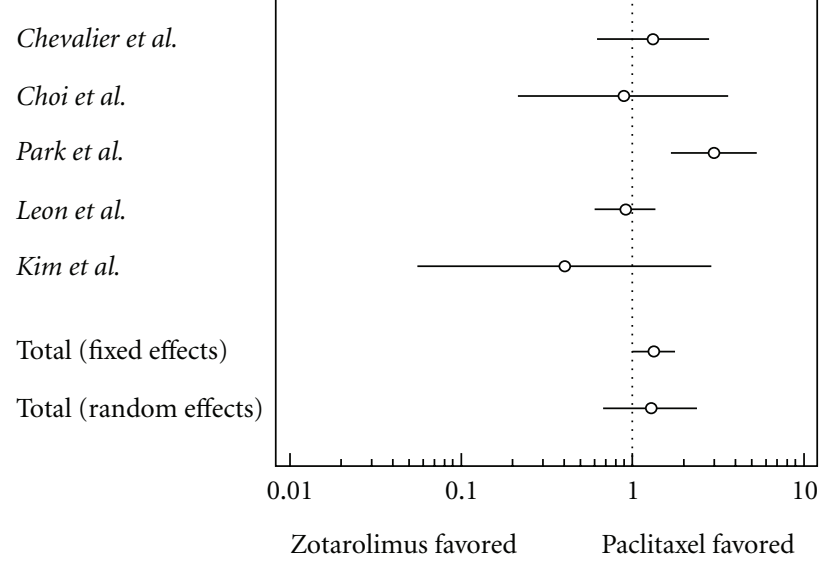

FIGURE 7: Forest plot comparing risk of target vessel revascularization. 


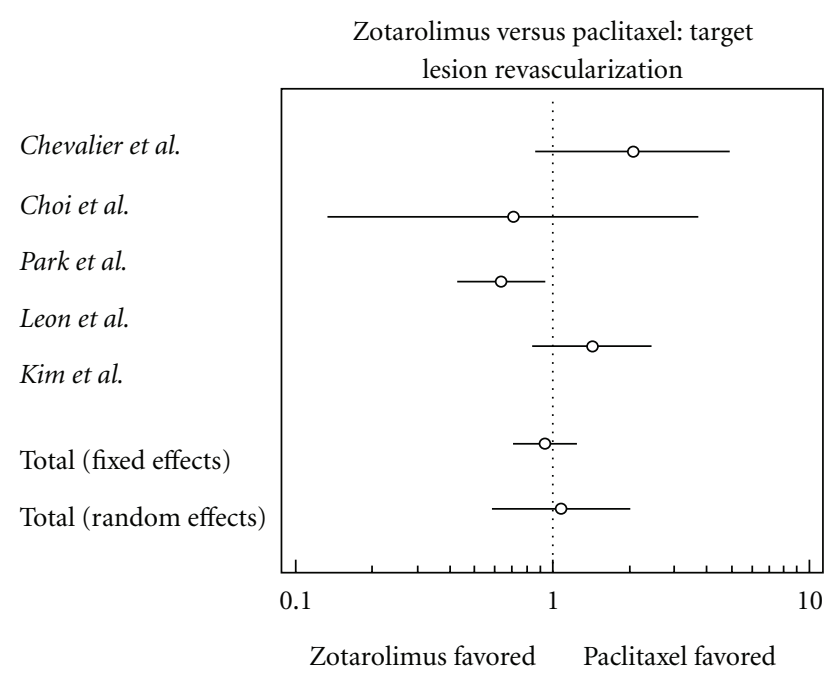

FIGURE 8: Forest plot comparing risk of target lesion revascularization.

Limitations of this meta-analysis include those inherent to all such analyses such as pooling of data from studies which may have slightly differing designs and heterogeneity. It should also be noted that ZoMaxx I included only 9-month follow-up data which was included in this study. As with any meta-analysis, publication and selection bias may have impacted results of this analysis.

\section{Conclusion}

The zotarolimus-eluting stents offer a safe option when selecting a drug-eluting stent. When compared to paclitaxeleluting stents, zotarolimus eluting stents are associated with a significantly lower risk of myocardial infarction while being associated with a significantly higher risk of need for target vessel revascularization. Additionally, studies have shown increased late loss in zotarolimus-eluting stents when compared to paclitaxel-eluting stents. This increased late loss should be kept in mind when zotarolimus-eluting stents are being considered. Comparison of 12-month outcomes does not seem to warrant the use of either stent over the other, particularly keeping in mind the absence of any advantage afforded by one stent in regards to cost-effectiveness.

\section{Financial Disclosures}

There are no financial disclosures to be made regarding this manuscript. All the authors have contributed to the manuscript and approved its submission. This manuscript has not been submitted to any other journal or has not been presented in any other form.

\section{Abbreviations}

CABG: Coronary artery bypass graft

MI: Myocardial infarction

MACE: Major adverse cardiac events

STEMI: ST-elevation myocardial infarction

PCI: Percutaneous coronary intervention.

\section{References}

[1] C. U. Choi, S. W. Rha, K. Y. Chen et al., "Lack of clinical benefit of improved angiographic results with sirolimuseluting stents compared with paclitaxel and zotarolimuseluting stents in patients with acute myocardial infarction undergoing percutaneous coronary intervention," Circulation Journal, vol. 73, no. 12, pp. 2229-2235, 2009.

[2] U. Kim, D. K. Kim, S. H. Seol et al., "Clinical and angiographic outcomes of drug-eluting stents in patients with large vessel and single coronary artery lesion," Clinical Cardiology, vol. 33, no. 6, pp. 340-344, 2010.

[3] B. Chevalier, C. Di Mario, F. J. Neumann et al., "A randomized, controlled, mutlicenter trial to evaluate the safety and efficacy of zotarolimus- versus paclitaxel-eluting stents in de novo occlusive lesions in coronary arteries," Journal of the American Collage of Cardiology, vol. 1, no. 5, pp. 524-532, 2008.

[4] C. W. Lee, D. W. Park, S. H. Lee et al., "Comparison of the efficacy and safety of zotarolimus-, sirolimus-, and paclitaxeleluting stents in patients with ST-elevation myocardial infarction," American Journal of Cardiology, vol. 104, no. 10, pp. 1370-1376, 2009.

[5] D. Cicek, H. Pekdemir, C. Haberal et al., "Two year outcome of turkish patients treated with zotarolimus versus paclitaxel elutings stents in an unselected population with coronary artery disease in the real world: a prospective non randomized registry in southern turkey," International Journal of Medical Sciences, vol. 8, no. 1, pp. 68-73, 2011.

[6] J. W. Moses, M. B. Leon, J. J. Popma et al., "Sirolimus-eluting stents versus standard stents in patients with stenosis in a native coronary artery," The New England Journal of Medicine, vol. 349, no. 14, pp. 1315-1323, 2003.

[7] G. J. Laarman, M. J. Suttorp, M. T. Dirksen et al., "Paclitaxeleluting versus uncoated stents in primary percutaneous coronary intervention," The New England Journal of Medicine, vol. 355, no. 11, pp. 1105-1113, 2006.

[8] C. Spaulding, P. Henry, E. Teiger et al., "Sirolimus-eluting versus uncoated stents in acute myocardial infarction," The New England Journal of Medicine, vol. 355, no. 11, pp. 10931104, 2006.

[9] M. Menichelli, A. Parma, E. Pucci, R. Fiorilli et al., "Randomized trial of sirolimus-eluting stent versus bare-metal stent in acute myocardial infarction," Journal of the American College of Cardiology, vol. 49, no. 19, pp. 1924-1930, 2007.

[10] G. W. Stone, J. W. Moses, S. G. Ellis et al., "Safety and efficacy of sirolimus- and paclitaxel-eluting coronary stents," The New England Journal of Medicine, vol. 356, no. 10, pp. 998-1008, 2007.

[11] A. Kastrati, J. Mehilli, J. Pache et al., "Analysis of 14 trials comparing sirolimus-eluting stents with bare-metal stents," The New England Journal of Medicine, vol. 356, no. 10, pp. 1030-1039, 2007.

[12] O. C. Marroquin, F. Selzer, S. R. Mulukutla et al., "A comparison of bare-metal and drug-eluting stents for off-label indications," The New England Journal of Medicine, vol. 358, no. 4, pp. 342-352, 2008.

[13] J. Carlsson, S. K. James, J. Lindbäck et al., "Outcome of drug-eluting versus bare-metal stenting used according to on- and off-label criteria," Journal of the American College of Cardiology, vol. 53, no. 16, pp. 1389-1398, 2009.

[14] S. J. Sollott, L. Cheng, R. R. Pauly et al., "Taxol inhibits neointimal smooth muscle cell accumulation after angioplasty in the rat," The Journal of Clinical Investigation, vol. 95, no. 4, pp. 1869-1876, 1995. 
[15] P. B. Schiff and S. B. Horwitz, "Taxol stabilizes microtubules in mouse fibroblast cells," Proceedings of the National Academy of Sciences, vol. 77, no. 3, pp. 1561-1565, 1980.

[16] D. W. Park, Y. H. Kim, S. C. Yun et al., "Comparison of zotarolimus-eluting stents with sirolimus- and paclitaxeleluting stents for coronary revascularization," The Journal of The American College of Cardiology, vol. 56, no. 15, pp. 1187$1195,2010$.

[17] L. E. Burke, J. Choo, E. Music et al., "PREFER study: a randomized clinical trial testing treatment preference and two dietary options in behavioral weight management-rationale, design and baseline characteristics," Contemporary Clinical Trials, vol. 27, no. 1, pp. 34-48, 2006. 


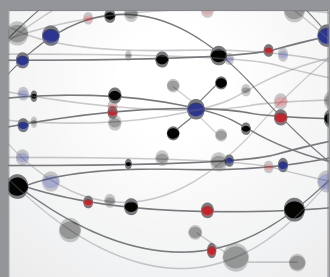

The Scientific World Journal
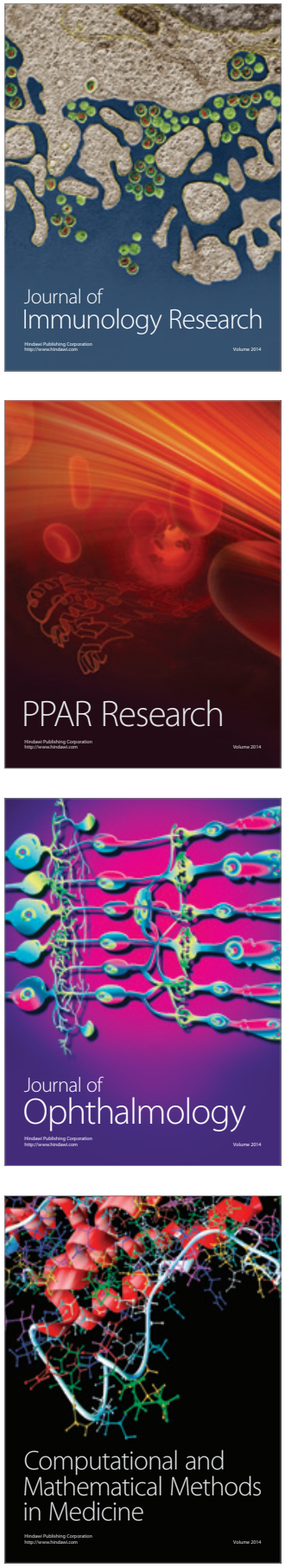

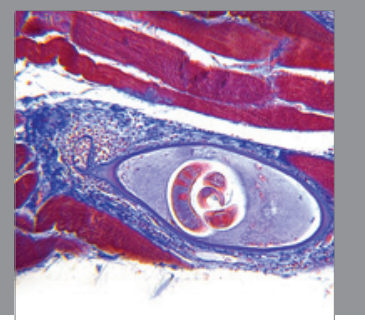

Gastroenterology

Research and Practice
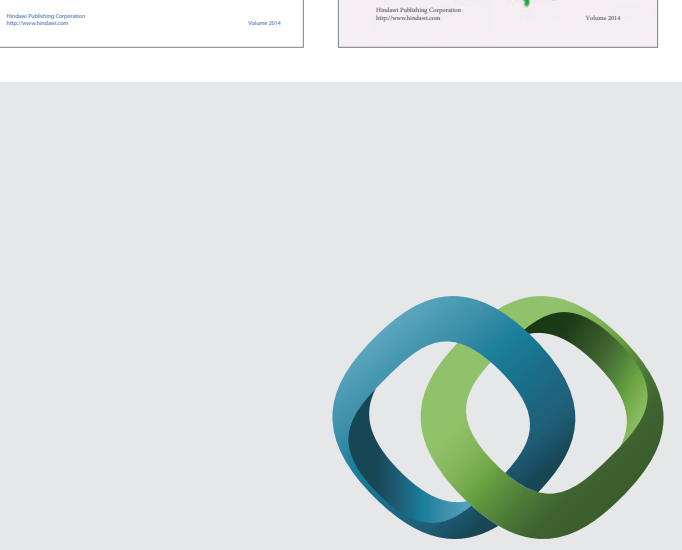

\section{Hindawi}

Submit your manuscripts at

http://www.hindawi.com
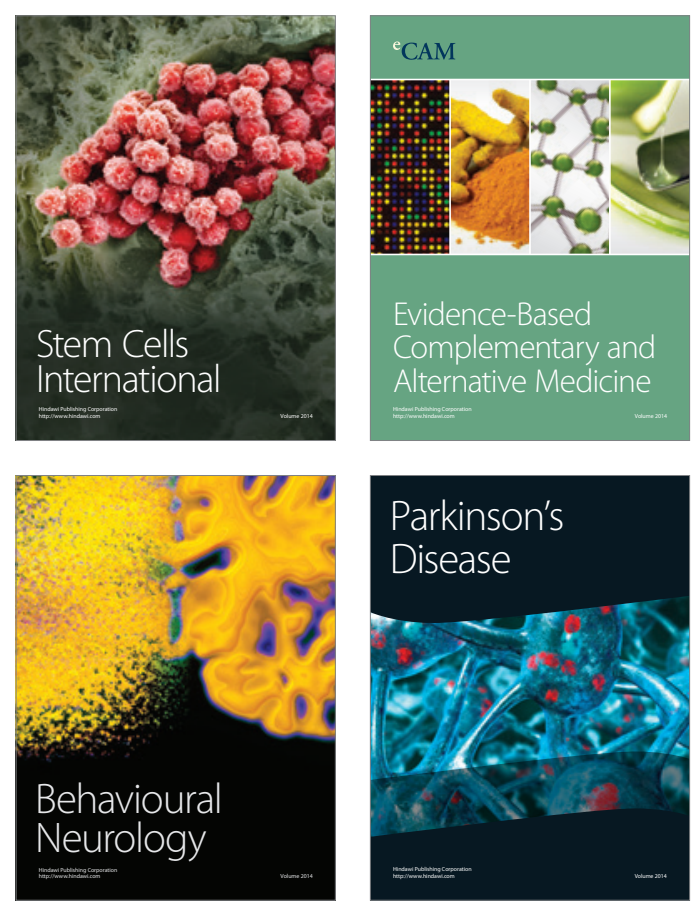

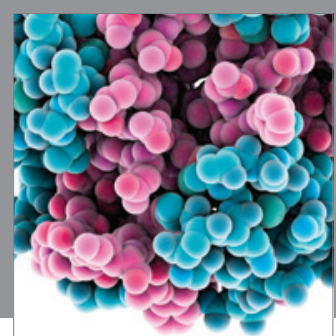

Journal of
Diabetes Research

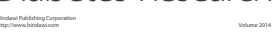

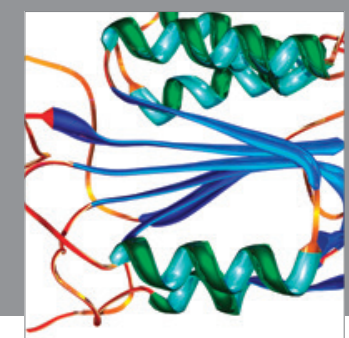

Disease Markers
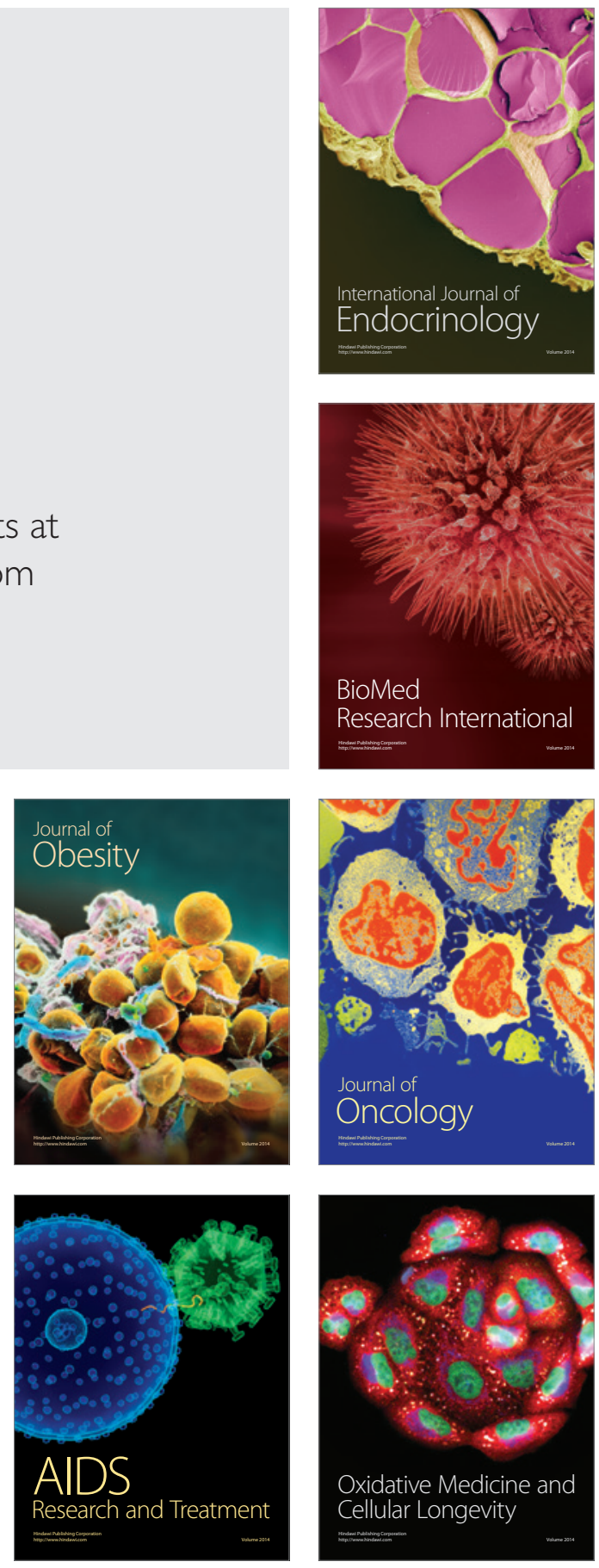